\title{
High Levels of Tetrodotoxin in the Flesh, Usually an Edible Part of the Pufferfish Takifugu flavipterus, Caused by Migration from the Skin and the Regional Characteristics of Toxin Accumulation
}

\author{
Naomasa Oshiro ${ }^{1, *(D)}$, Kyoko Kuniyoshi ${ }^{1}$, Shigeyoshi Yamamoto ${ }^{1,2}$, Ayano Hotta ${ }^{1,2,3}$, Takuma Yamada ${ }^{1,2}$, \\ Takafumi Suzuki ${ }^{1,2}$, Noriko Sugita ${ }^{1,2}$, Keiichi Matsuura ${ }^{4}$, Akie Nakashima ${ }^{5}$, Yoichi Anzai ${ }^{6}$ \\ and Hiroshi Asakura ${ }^{1}$ (D)
}

check for updates

Citation: Oshiro, N.; Kuniyoshi, K.; Yamamoto, S.; Hotta, A.; Yamada, T.; Suzuki, T.; Sugita, N.; Matsuura, K.; Nakashima, A.; Anzai, Y.; et al. High Levels of Tetrodotoxin in the Flesh, Usually an Edible Part of the Pufferfish Takifugu flavipterus, Caused by Migration from the Skin and the Regional Characteristics of Toxin Accumulation. J. Mar. Sci. Eng. 2021, 9, 1312. https://doi.org/10.3390/ jmse9111312

Academic Editor: Pedro Reis Costa

Received: 7 November 2021

Accepted: 19 November 2021

Published: 22 November 2021

Publisher's Note: MDPI stays neutral with regard to jurisdictional claims in published maps and institutional affiliations.

Copyright: (c) 2021 by the authors. Licensee MDPI, Basel, Switzerland. This article is an open access article distributed under the terms and conditions of the Creative Commons Attribution (CC BY) license (https:// creativecommons.org/licenses/by/ $4.0 /)$.
1 National Institute of Health Sciences, 3-25-26 Tonomachi, Kawasaki 210-9501, Kanagawa, Japan; k-kuniyoshi@nihs.go.jp (K.K.); Ayano_1_Hotta@member.metro.tokyo.jp (A.H.); hasakura@nihs.go.jp (H.A.)

2 Department of Pharmacy and Health Sciences, Meiji Pharmaceutical University, 2-522-1 Noshio, Kiyose 204-8588, Tokyo, Japan

3 Tokyo Metropolitan Institute of Public Health, 3-24-1 Hyakunin-cho, Shinjuku 169-0073, Tokyo, Japan

4 National Museum of Nature and Science, 4-1-1 Amakubo, Tsukuba 305-0005, Ibaraki, Japan; matsuura@kahaku.go.jp

5 Hiroshima Prefectural Technology Research Institute, Health and Environment Center, 1-6-29 Minamimachi, Minami 734-0007, Hiroshima, Japan; a-nakashima81167@pref.hiroshima.lg.jp

6 Food Sanitation Division, Health Department, Health and Welfare Bureau, The City of Hiroshima, 11-27 Fujimi-cho, Naka-ku 730-8586, Hiroshima, Japan; anzai-y@city.hiroshima.lg.jp

* Correspondence: n-oshiro@nihs.go.jp

Abstract: The consumption of a pufferfish, Takifugu flavipterus or komonfugu in Japanese, formerly known as Takifugu poecilonotus, is popular in Japan. However, T. flavipterus is frequently involved in cases of tetrodotoxin (TTX) poisoning in Japan. Although victims have usually consumed inedible parts, some cases are related to consumption of flesh. To improve the risk management of pufferfish poisoning, we studied TTX level in the flesh and skin of T. flavipterus. Ninety-seven specimens obtained from the Seto Inland Sea and landed in Fukuoka Prefecture were analyzed by liquid chromatography-tandem mass spectrometry. The flesh from six specimens was toxic ( $>10 \mathrm{MU} / \mathrm{g}=2.2 \mathrm{mg} / \mathrm{kg}$ ): one was in poor condition (not freeze-thawed); three were freeze-thawed before sample preparation; and two freshly prepared and in good condition (not freeze-thawed). The fillets were divided into outer and inner portions; the TTX levels in the outer portions were notably higher. The skin of the six specimens was moderately to extremely toxic: $165 \mathrm{MU} / \mathrm{g}$ (36.3 mg/kg) in the fresh specimen not in good condition, $600-950 \mathrm{MU} / \mathrm{g}(132-200 \mathrm{mg} / \mathrm{kg})$ in freeze-thawed specimens, and 4500 and $6000 \mathrm{MU} / \mathrm{g}$ (990 and $1320 \mathrm{mg} / \mathrm{kg}$ ) in the two fresh specimens. We concluded that TTX in the flesh migrated from the highly toxic skin. In addition, TTX levels in the skin appeared to be regionally specific. We recommend that toxic portions of T. flavipterus are removed as soon as possible after individuals are caught, and that fish from known highly toxic areas are not consumed.

Keywords: Takifugu flavipterus; Takifugu poecilonotus; tetrodotoxin; LC-MS/MS

\section{Introduction}

Pufferfish is a common delicacy in East Asia, particularly Japan. However, it is also known to be poisonous, as it contains the potent neurotoxin tetrodotoxin (TTX), as well as TTX analogs. TTX is the most abundant of the neurotoxins in pufferfish and is the most toxic compounds [1]. Many cases of intoxication due to the consumption of TTX accumulated in pufferfishes have been reported; these have occurred mainly in East and Southeast Asia, especially Japan [2-6]. 
In accordance with the Japanese Food Sanitation Act (Act No.233 of 24 December, 1947), pufferfishes are categorized as containing toxic substances prohibited from being handled as foods. Article 6, Item (ii) of the Act, ban from handling the stuff containing toxins with the proviso that "this shall not apply to cases where the Minister of Health, Labour and Welfare specifies that such articles involve no risk to human health" [7]. Following this proviso, the Ministry of Health, Labour and Welfare of Japanese Government (MHLW) provided the notice entitled "New Rules for Measures to Secure Sanitation Regarding Pufferfish" (Kan-Nyu59 of 2 December, 1983). The notice contained the list "Species and parts that can be processed to eliminate health risks" (Table A1) and permitted only licensed persons to handle and treat to remove the toxic tissues from the pufferfish, to allow human consumption [7]. The list also stated that individuals of Takifugu flavipterus and Takifugu pardalis caught in Okirai, Kamaishi, and Ogatsu Bays, along the Pacific coast of northern Honshu Island, were inedible because they contained high levels of toxins in their flesh. Among 57 specimens of T. flavipterus, $90 \%$ of the flesh samples were toxic (>10 MU/g); the highest level was $350 \mathrm{MU} / \mathrm{g}$ (1 mouse unit (MU) is defined as the toxicity that lethal to a male mouse with a body weight of $20 \mathrm{~g}$ in $30 \mathrm{~min}$ ) [8]. Despite this system, incidents of pufferfish poisoning occur every year, including fatal cases [4]. However, in most cases, the victims or their relatives captured and cooked the fish implicated, without a license or knowledge of to handle pufferfish. The most involved species was T. flavipterus, known as Komonfugu in Japanese (Figure 1); most of the cases were from Hiroshima Prefecture, which faces the Seto Inland Sea, and Fukuoka Prefecture, located in northern Kyushu Island [4]. Takifugu poecilonotus was assigned for this species, but recently, Matsuura found a taxonomic problem with this scientific name and described it as a new species, T. flavipterus [9]. As stated in the list provided by the MHLW, the flesh of T. flavipterus is edible, but the other parts, including the skin, testis, ovary, and liver, are inedible (Table A1). In most cases of poisoning, the victims consumed inedible parts, including the liver, ovary, and skin; however, some cases were due to consumption of the flesh.

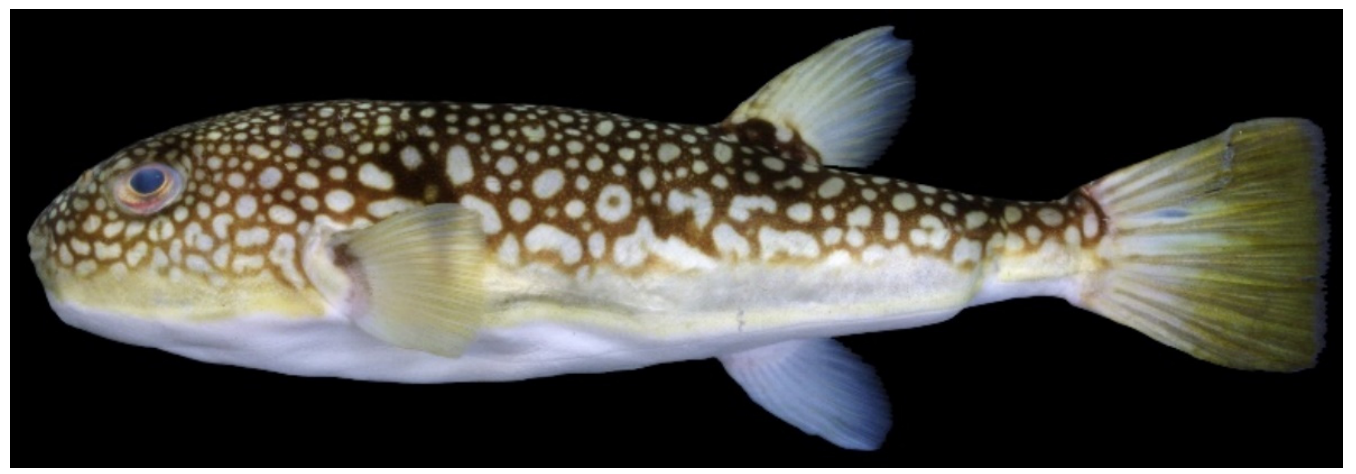

Figure 1. A pufferfish Takifugu flavipterus (KAUM-I. 80923). The photograph was taken by Professor Hiroyuki Motomura, Kagoshima University.

In this study, we analyzed the TTX levels in the flesh and skin of T. flavipterus specimens captured from the Seto Inland Sea and landed in Fukuoka Prefecture, Japan, to verify the risk management of pufferfish poison, as provided in the list by MHLW.

\section{Materials and Methods}

\subsection{Reference Toxin and Reagents}

Tetrodotoxin for Biochemistry (1 mg, FUJIFILM Wako Chemical Industry, Ltd., Osaka, Japan) was dissolved in water $(1 \mathrm{~mL})$, quantified by a certified reference material of tetrodotoxin (CRM-03-TTXs, tetrodotoxin, 4,9-anhydrotetrodotoxin) purchased from Laboratorio CIFGA S.A. (Lugo, Spain), and used as the TTX reference solution. Acetic acid (guaranteed reagent grade), acetonitrile (liquid chromatography-mass spectrometry (LC-MS)) grade, ammonium formate solution (1 mol/L), and formic acid of the high- 
performance liquid chromatography (HPLC) grade were purchased from FUJIFILM Wako Chemical Industry, Ltd. (Osaka, Japan). Ultrapure water was supplied by Milli- $Q^{\circledR}$ Integral Water Purification System for Chemical Analysis (Millipore, Bedford, MA, USA).

\subsection{Specimens}

Pufferfish, Takifugu flavipterus, was purchased from a fish retailer between October 2015 and January 2016 (Table 1, Figure 2). The fresh specimens were packed in plastic, soaked in ice water, and transferred to the National Institute of Health Sciences (NIHS). After the specimens arrived at the NIHS, they were weighed and their standard length was measured. Pictures of the lateral and dorsal sides and fins were used to identify the fish species by one of the authors (K.M.). One of the specimens, which was not used for TTX analysis, was send to Prof. Hiroyuki Motomura; the Kagoshima University Museum has a voucher specimen (KAUM-I. 80923). The specimens were cut into the skin, fillet, liver, and other internal organs on day of their arrival and stored in plastic bags at $-30{ }^{\circ} \mathrm{C}$ until use. If this treatment could not be carried on the day when the specimens arrived, the specimens were stored at $-30^{\circ} \mathrm{C}$. The frozen specimens were half-thawed under running water, and separated into tissues, as described above.

Table 1. The capture sites and dates, and number of specimens of the pufferfish, Takifugu flavipterus.

\begin{tabular}{ccc}
\hline Capture Site & Captured Date & Number of Specimens \\
\hline A & 30 October 2015 & 6 \\
B & 5 November 2015 & 8 \\
C & 17 November 2015 & 15 \\
D & 1 December 2015 & 15 \\
E & 7 December 2015 & 6 \\
F & 15 December 2015 & 30 \\
G & 20 January 2016 & 17 \\
\hline Total & & 97 \\
\hline
\end{tabular}

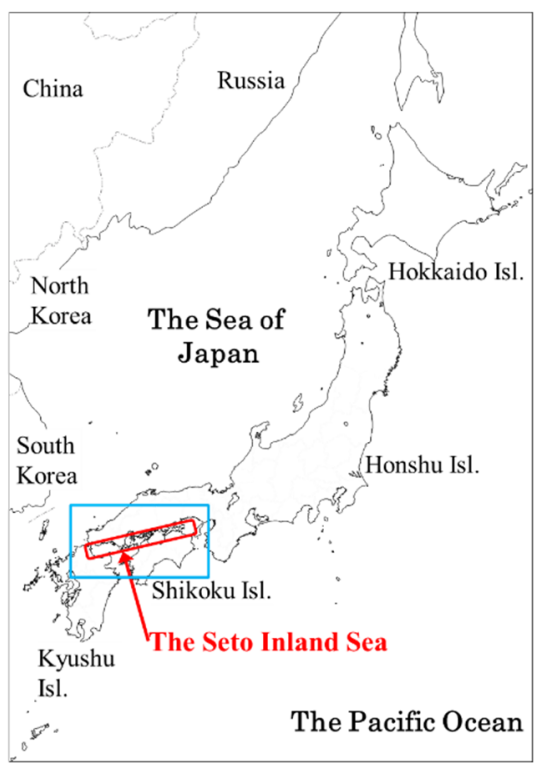

(a)

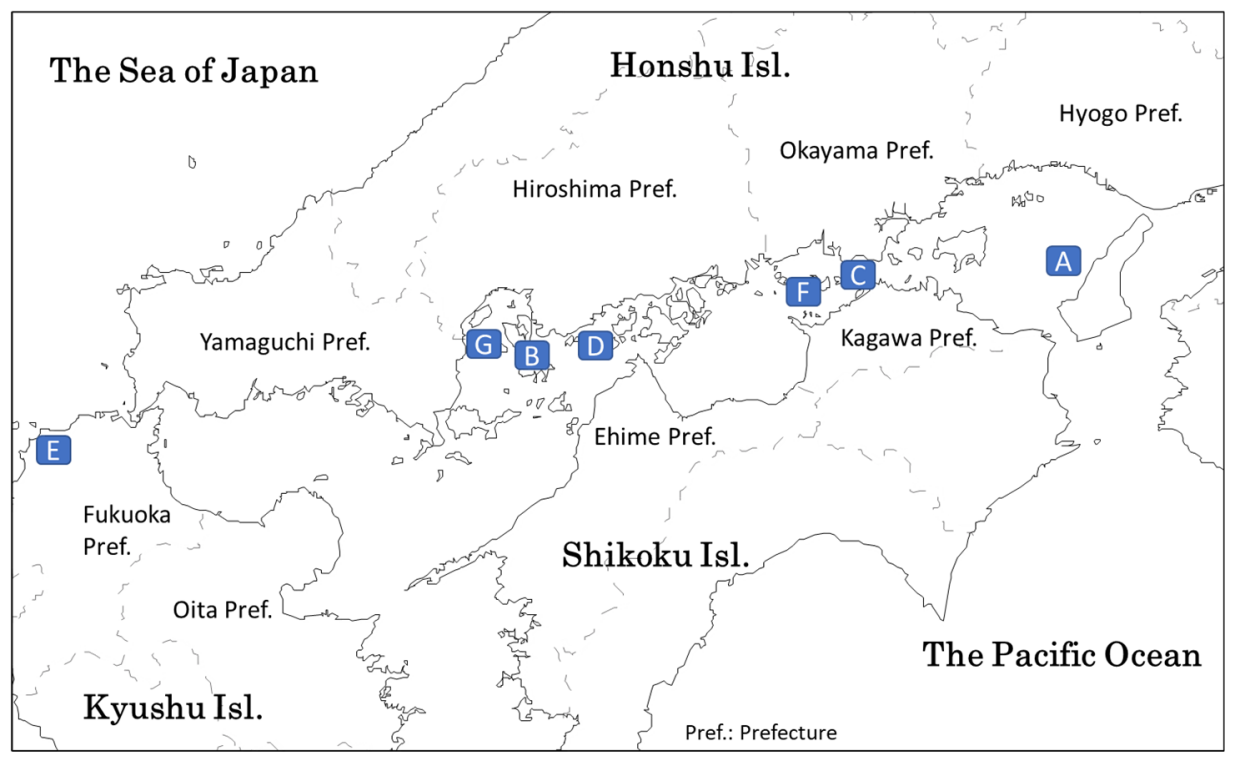

(b)

Figure 2. The location of the captured area of the pufferfish, Takifugu flavipterus, specimens. (a) Location of the Seto Inland Sea in Japan; (b) captured sites A to G. 


\subsection{Sample Preparation}

\subsubsection{Flesh Sample Randomly Taken from Fillets}

Frozen fillet samples were half-thawed under running water, and three portions of 2-g flesh were taken from random locations in the fillet. Each flesh sample was homogenized with $0.1 \%$ acetic acid $(v / v, 8 \mathrm{~mL})$, and then heated in boiling water (10 $\mathrm{min})$. After it was cooled at room temperature, it was centrifuged $(13,400 \times g, 15 \mathrm{~min})$, and the supernatant was collected to obtain the crude extract. A $0.1 \mathrm{~mL}$ portion of the crude extract was mixed with $0.1 \%$ acetic acid $(v / v, 0.9 \mathrm{~mL})$ and ultra-filtrated with Pall Nanosep ${ }^{\circledR}$ Centrifugal Devices (Omega ${ }^{\mathrm{TM}}$ Membrane $10 \mathrm{~K}$, Nihon Pall Ltd., Tokyo, Japan). The filtrate (0.5 mL) was mixed with acetonitrile $(0.5 \mathrm{~mL})$, and a $0.5 \mathrm{~mL}$ aliquot of the mix was filtered with using a Single StEP Filter vial (0.2 $\mu \mathrm{m}$ PVDF, Thomson Instrument Company, Oceanside, CA, USA) to prepare it for analysis. The three solutions for each specimen were analyzed by LC-MS/MS.

\subsubsection{Exploring the Origin of the TTX in Flesh}

The fillet samples remaining in frozen were half thawed and divided into two portions, namely the outer (skin side) and inner (visceral side) parts. Each part was homogenized. Three portions $2 \mathrm{~g}$ were taken from each homogenate and were treated as described above to obtain the solutions for LC-MS/MS analysis.

The half-thawed skin sample was chopped into small pieces and $2 \mathrm{~g}$ was taken to prepare a sample solution for LC-MS/MS analysis, as described above (Section 2.3.1).

\section{4. $L C-M S / M S$}

The LC-MS/MS analysis was conducted on an Agilent 1290 HPLC system coupled with an Agilent 6460 Triple Quadrupole MS instrument (Santa Clara, CA, USA). A $5 \mu \mathrm{L}$ aliquot of the solution was chromatographed with Inertsil Amide $(3 \mu \mathrm{m}, 2.1 \times 75 \mathrm{~mm})$ or InertSustain Amide $(3 \mu \mathrm{m}, 2.1 \times 75 \mathrm{~mm})$ at $45^{\circ} \mathrm{C}$ using a mixture of acetonitrile and water $(25: 75, v / v)$ containing $0.5 \mathrm{mM}$ formic acid and $0.25 \mathrm{mM}$ ammonium formate with a flow rate of $0.5 \mathrm{~mL} / \mathrm{min}$ in isocratic mode. The parameters of the MS were set as follows: ionization, ESI (positive) equipped with Agilent Jet Stream technology; dry gas, $\mathrm{N}_{2}, 280^{\circ} \mathrm{C}, 12 \mathrm{~L} / \mathrm{min}$; nebulizer gas, $\mathrm{N}_{2}, 50 \mathrm{psi}$; sheath gas, $\mathrm{N}_{2}, 350{ }^{\circ} \mathrm{C}, 11 \mathrm{~L} / \mathrm{min}$; capillary voltage, $3500 \mathrm{~V}$; nozzle voltage, $500 \mathrm{~V}$; fragmentor voltage, $135 \mathrm{~V}$; collision gas, $\mathrm{N}_{2}$, collision energy, $35 \mathrm{eV}$. The mass transitions of $\mathrm{m} / \mathrm{z} 320.2>\mathrm{m} / \mathrm{z} 162.1$ and $\mathrm{m} / \mathrm{z} 320.2>\mathrm{m} / \mathrm{z} 302.0$ were monitored in multiple reaction monitoring (MRM) mode as the quantitative and qualitative ions, respectively. The limit of detection (LOD) and the limit of quantification (LOQ) in this study were estimated based on the signal-to-noise ratio $(\mathrm{S} / \mathrm{N})$ of reference solution, and were $0.05 \mathrm{ng} / \mathrm{mL}(0.09 \mathrm{MU} / \mathrm{g}: \mathrm{s} / \mathrm{n}>3)$ and $0.25 \mathrm{ng} / \mathrm{mL}(0.45 \mathrm{MU} / \mathrm{g}: \mathrm{s} / \mathrm{n}>10)$, respectively. The calibration range was $0.25-25 \mathrm{ng} / \mathrm{mL}$.

\subsection{Toxicity Evaluation}

The toxicity of the pufferfish has been evaluated based on mouse bioassay expressed in MU/g in Japan. One MU is defined as the amount of toxin that causes the death of a male mouse with a body weight of $20 \mathrm{~g}$ in $30 \mathrm{~min}$ following intraperitoneal administration, and is equivalent to $0.22 \mathrm{mg}$ of tetrodotoxin $[10,11]$. The toxicity scores of pufferfish have been classified based on the minimum lethal dose of TTX (10,000 MU/person) as shown in Table 2: nontoxic, $<10 \mathrm{MU} / \mathrm{g}(<2.2 \mathrm{mg}$ TTX/kg); moderately toxic, $10-100 \mathrm{MU} / \mathrm{g}$ (2.2-22 mg TTX/kg); strongly toxic, 100-1000 MU/g (22-220 mg TTX/kg); extremely toxic, $>1000 \mathrm{MU} / \mathrm{g}(>220 \mathrm{mg}$ TTX/kg) ([2]. In a review paper [2], the toxicity score was defined for 10-100 MU/g as weakly toxic, 100-1000 MU/g as moderately toxic, and >1000 MU strongly toxic. However, 10-100 MU/g may cause human intoxication. Thus, the scores were redefined as described above in the present study. Thus, the observed levels of TTX in pufferfish explained in $\mathrm{mg} / \mathrm{kg}$ were converted to the toxicity in MU/g using the conversion of $0.22 \mathrm{mg} / \mathrm{MU}$ in this study. 
Table 2. Toxicity scores of the tissue of pufferfish.

\begin{tabular}{|c|c|c|}
\hline Score & TTXs Level (MU/g) & TTX Equivalent $(\mathrm{mg} / \mathrm{kg})^{1}$ \\
\hline Non toxic & $<10$ & $<2.2$ \\
\hline Moderately toxic & $10-100$ & $2.2-22$ \\
\hline Strongly toxic & $100-1000$ & $22-220$ \\
\hline Extremely toxic & $>1000$ & $>220$ \\
\hline
\end{tabular}

${ }^{1}$ TTX equivalent was deduced from that $1 \mathrm{MU}$ was equivalent to $0.22 \mathrm{mg}$ of TTX.

\section{Results and Discussion}

\subsection{Toxicity of the Flesh Samples Randomly Taken from Fillets}

From flesh samples of 97 specimens analyzed $(n=3)$, six specimens (NIHS-150040, $150051,150052,150054,150091$, and 150097) were identified as toxic ( $>10 \mathrm{MU} / \mathrm{g}=2.2 \mathrm{mg} / \mathrm{kg})$. Pictures are shown in Figure 3 and LC-MS/MS MRM chromatograms of the reference toxin and the representative sample are shown in Figure 4.

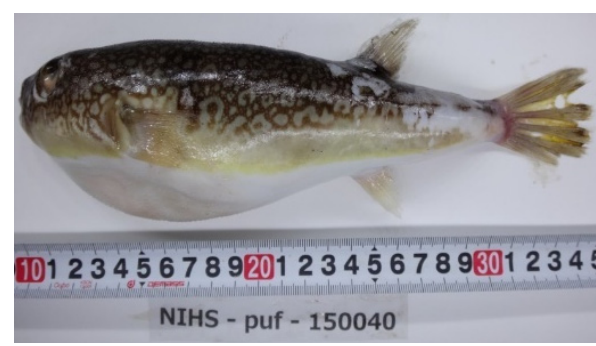

(a)

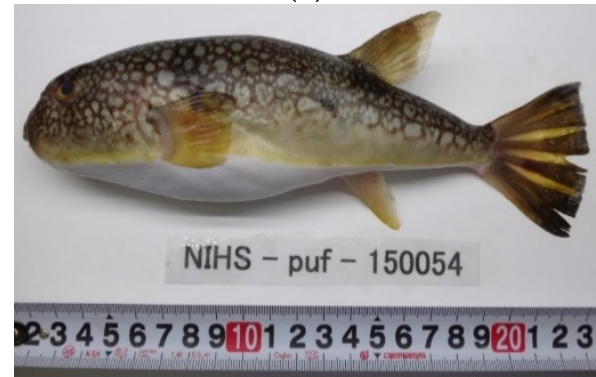

(d)

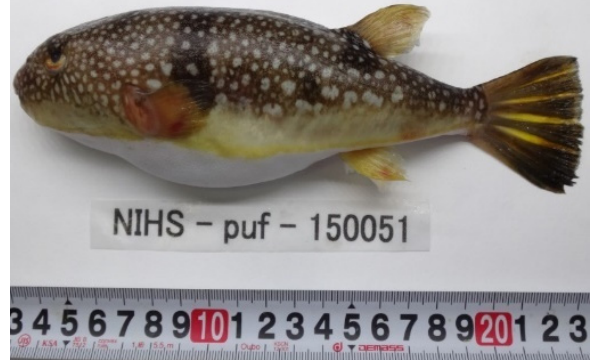

(b)

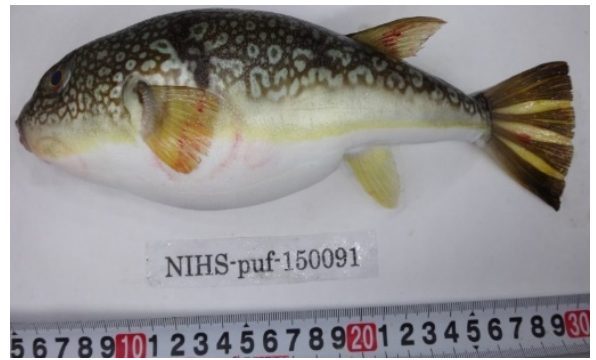

(e)

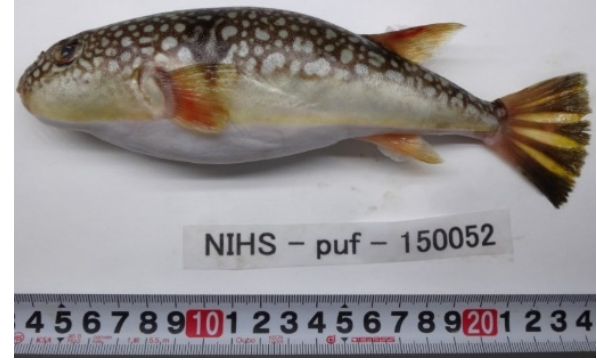

(c)

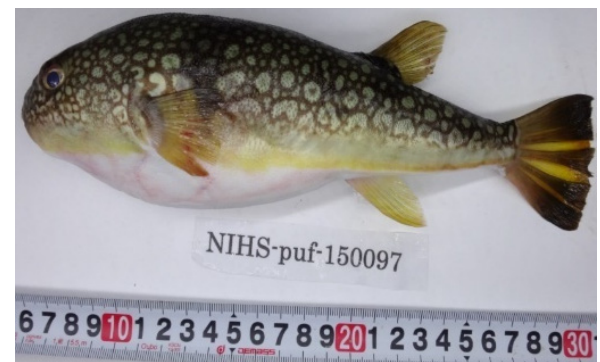

(f)

Figure 3. The toxic specimens of the puffer fish, Takifugu flavipterus, captured from Seto Inland Sea, Japan. (a) NIHS-puf150040: without freeze-thaw, but not in good condition. (b) NIHS-puf-150051, (c) 150052, and (d) 150054: freeze-thawed before cutting into each tissue (flesh and skin). (e) NIHS-puf-150091 and (f) 150097: not freeze-thawed.

The levels of TTX (average of $n=3$ ) in toxic specimens were 12-33 MU/g and the relative standard deviations (RSD) was 7.6\%-91\% (Table 3). The highest level of TTX, more than two times the rest of the five specimens, was detected in NIHS-150040, and RSD was moderate $(7.6 \%)$. The condition of this specimen when we received at NIHS was not good. As shown in Figure 3a, the specimen appeared to be damaged with collapsed skin and fins. The TTX levels of remaining five specimens were similar (12-16 MU/g), but the RSD ranged from 24\%-91\% (Table 3). Of these samples, three (NIHS-150051, 150052, and 150054) were freeze-thawed before cutting into each tissue (flesh and skin) and no apparent abnormality was found in their appearance. Two samples (NIHS-150091 and 150097) were prepared within the day of their arrival without freezing. It has been well known that the skin of T. flavipterus was strongly toxic [2] and is banned from human consumption in Japan, as shown in Table A1. A significant RSD value within the triplicate analyses of the toxic flesh samples led us to consider the possibility of the TTX migration from skin to flesh. 


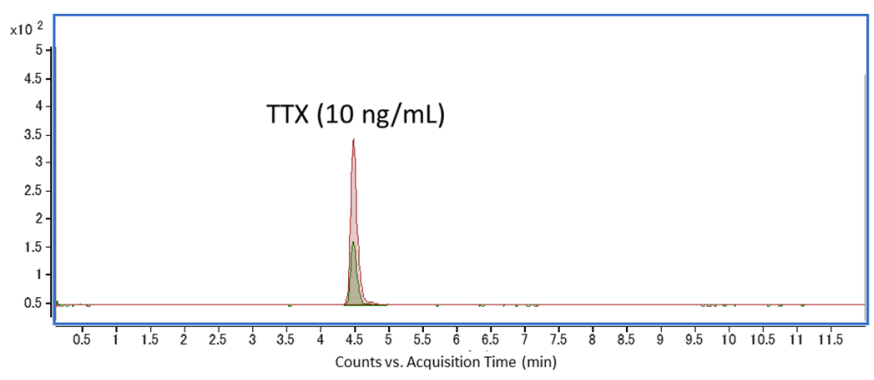

(a)

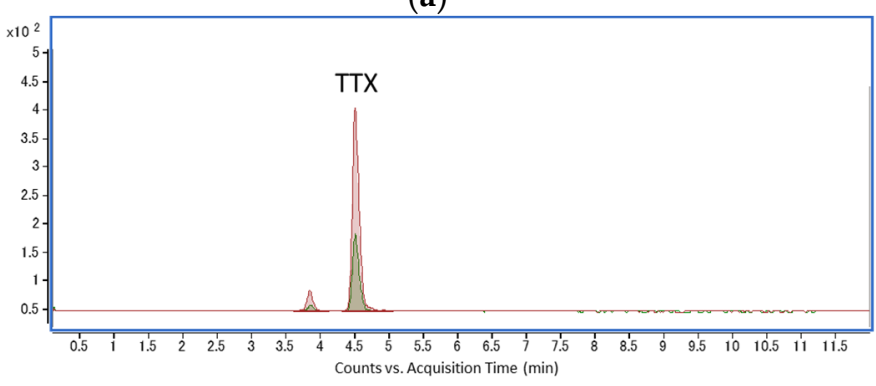

(c)

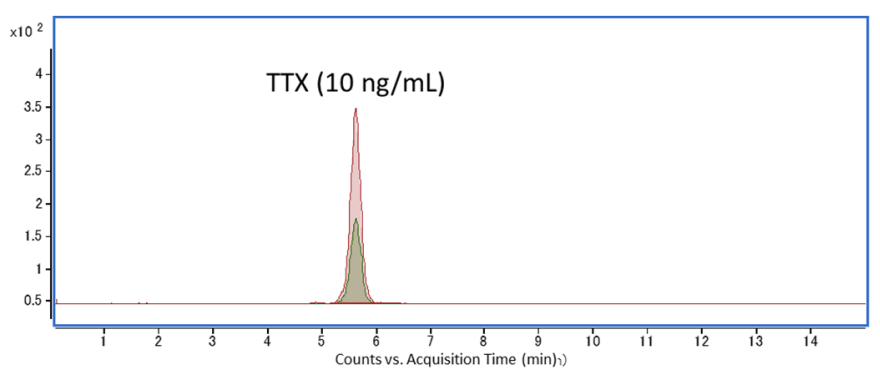

(b)

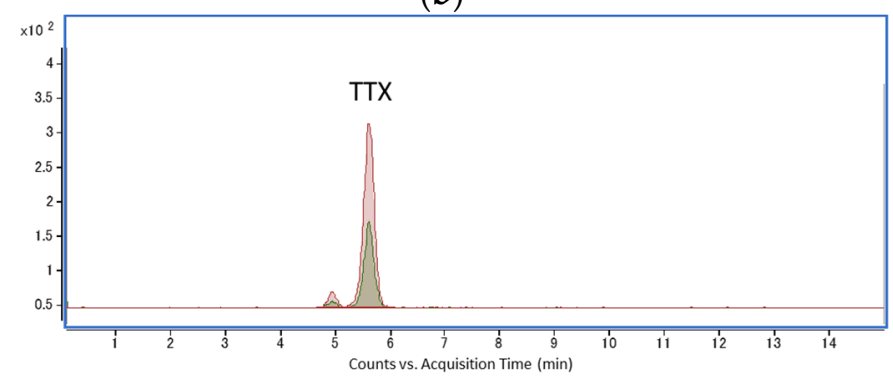

(d)

Figure 4. The LC-MS/MS MRM (m/z $320.2>\mathrm{m} / \mathrm{z} 162.1$ and $\mathrm{m} / \mathrm{z} 320.2>\mathrm{m} / \mathrm{z} 302.0)$ chromatograms of reference tetrodotoxin and a representative sample. $(\mathbf{a}, \mathbf{b})$, TTX reference solution $(10 \mathrm{ng} / \mathrm{mL}) ;(\mathbf{c}, \mathbf{d})$, flesh and skin samples, respectively, of specimen NIHS-140040. Analytical columns used were Inertsil Amide $(3 \mu \mathrm{m}, 2.1 \times 75 \mathrm{~mm})$ for $(\mathbf{a}, \mathbf{c})$, and InertSustain Amide $(3 \mu \mathrm{m}, 2.1 \times 75 \mathrm{~mm})$ for $(\mathbf{b}, \mathbf{d})$.

Table 3. TTX levels in the flesh samples randomly taken from fillets judged as toxic (>10 MU/g).

\begin{tabular}{cccc}
\hline Specimen ID & TTX Level (MU/g) $^{\mathbf{1}}$ & RSD (\%) $^{\mathbf{2}}$ & Remark \\
\hline NIHS-puf-150040 & 33 & 7.6 & Not good condition $^{\text {(M) }}$ \\
NIHS-puf-150051 & 16 & 36 & Freeze-thawed $^{3}$ \\
NIHS-puf-150052 & 13 & 42 & Freeze-thawed \\
NIHS-puf-150054 & 14 & 63 & Freeze-thawed \\
NIHS-puf-150091 & 14 & 91 & \\
NIHS-puf-150097 & 12 & 24 & \\
\hline
\end{tabular}

${ }^{1}$ TTX equivalent was deduced from $1 \mathrm{MU}$ was equivalent to $0.22 \mathrm{mg}$ of TTX; the levels were average of triplicate analyses. ${ }^{2}$ RSD: relative standard deviation. ${ }^{3}$ Specimens were frozen and thawed before cutting into each tissue.

\subsection{Analysis of the Outer and Inner Parts of the Flesh}

To elucidate the reason for the high TTX levels detected in the flesh samples, the fillet samples of the pufferfish specimens were divided into two sections, outer (skin side) and inner (organ side). Each portion was homogenized, extracted, and analyzed by LC-MS/MS. In almost all samples, TTX levels in the outer portions were higher than those in the inner portions, as shown in Figure 5. This result indicated the possibility of the migration of TTX from the toxic skin to the flesh. 


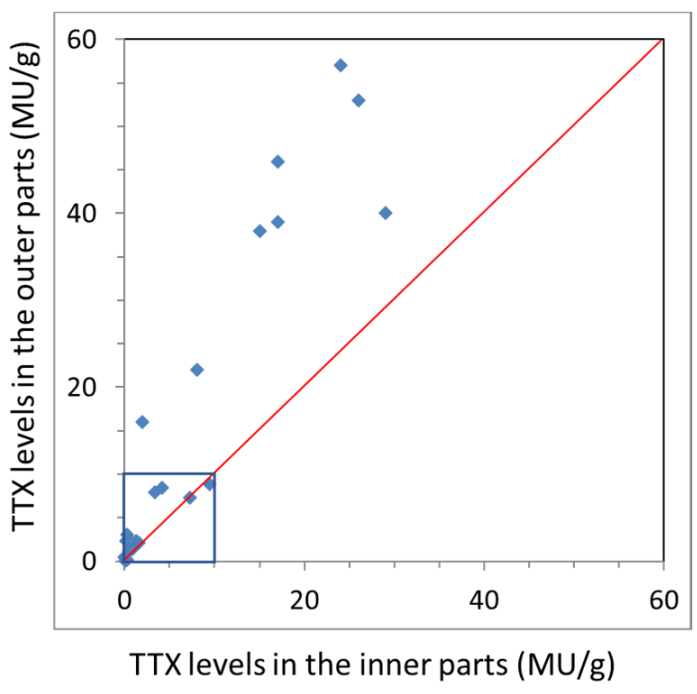

(a)

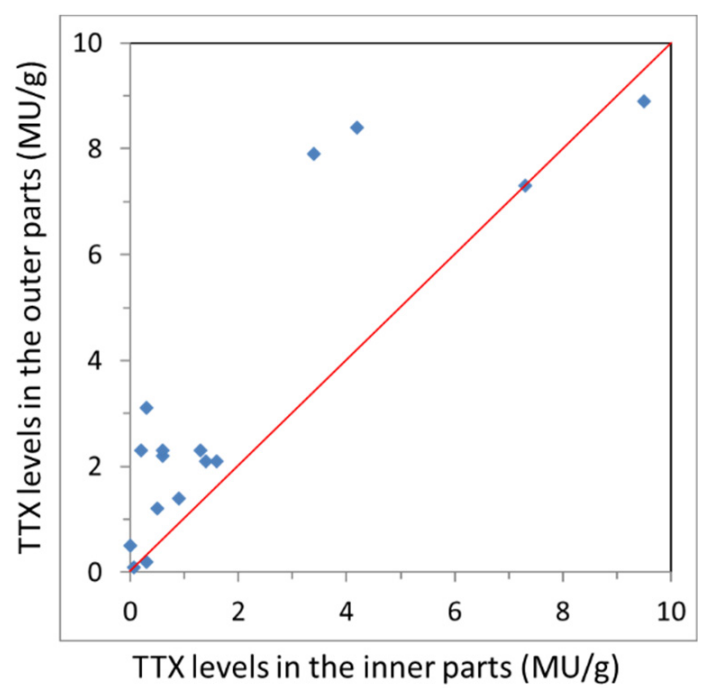

(b)

Figure 5. Relationship of TTX levels in the inner and outer parts of flesh of Takifugu flavipterus. (a) All specimens and (b) the expansion of the square indicated in (a). Red line: TTX levels in the outer parts = TTX levels in the inner parts.

\subsection{TTX Levels in the Skin}

The TTX levels in the skin samples ranged from 10 to $6000 \mathrm{MU} / \mathrm{g}$ (990 to $1320 \mathrm{mg} / \mathrm{kg}$ ), as shown in Figure 6. In addition, TTX levels in the skin appeared to be region-specific, rather than seasonally variable (Figure 5). There appeared to be no correlation between collection day and toxicity (the collection dates were in the order from A to G). However, the range of TTX levels appeared to be characteristic of the collection site, as follows: site A: all samples were moderately toxic; site B: most were strongly toxic; site C: most were moderate and some strongly toxic; site D: most were strongly and some extremely toxic; site E: most were strongly toxic; site F: most were moderately and some were strongly toxic; and site G: most were extremely and some strongly toxic (Figure 6). As shown in Figure 2, sites $B, D$, and $G$, which included the extremely toxic specimens, were located on the west coast of Hiroshima. Site A was located at the eastern end of the Seto Inland Sea, where only moderately toxic specimens were present.

In previous studies, specimens from Yamaguchi Prefecture, west of Hiroshima Prefecture, facing the Seto Inland Sea and the Sea of Japan, more than $50 \%$ of skin specimens were strongly (>100 MU/g) to extremely (1000 MU/g) toxic, and the highest toxicity observed was $6100 \mathrm{MU} / \mathrm{g}$ [12]. The TTX levels of the specimens from the Sea of Japan were higher than those from the Seto Inland Sea. For the specimens from Oita Prefecture in Northeast Kyushu Island, located at the eastern end of the Seto Inland Sea, most of the skin samples were strongly or extremely toxic. The highest level was $1500 \mathrm{MU} / \mathrm{g}$ [13]. In the specimens from the Ariake Sea, the largest bay Kyushu Island and located Northwest of Kyushu, the skin toxicity was $809 \pm 550 \mathrm{MU} / \mathrm{g}$ and $585 \pm 416 \mathrm{MU} / \mathrm{g}$, in female and male specimens, respectively [14]. These data were comparable with our present observations.

Asakawa and co-workers reported that a ribbon worm Cephalothrix simula adherent to cultured oysters in Hiroshima Bay accumulated high levels of TTX. Of the 615 individuals examined, $81 \%$ were extremely toxic $(>1000 \mathrm{MU} / \mathrm{g})$, with the maximum levels of 25,590 MU/g and 13,113 MU/individual. The amount of TTX accumulated in the worm was 2.5 times the human lethal dose [15-17]. Interestingly, T. flavipterus, together with sea bream Acanthopagrus schlegelii, were reported as major predatory fishes around oyster rafts, and they fed on oyster cultured in Hiroshima Bay [18]. This worm may contribute to the accumulation of TTX in T. flavipterus. Further environmental investigation, including toxicities of benthos such as $A$. schlegelii, should be carried out to elucidate the etiology of T. flavipterus toxicity. 


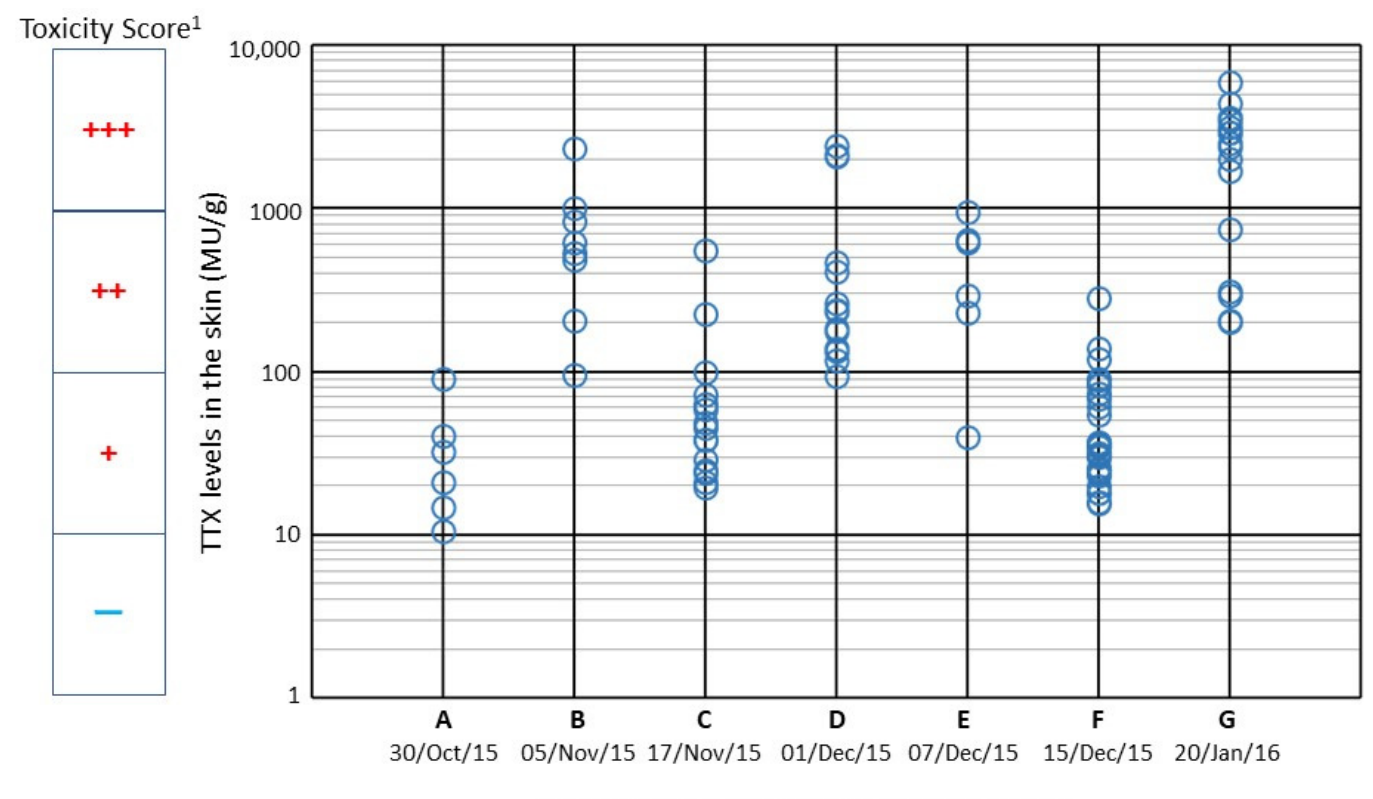

Captured area and date of the specimens ${ }^{2}$

Figure 6. TTX levels in the skin of the pufferfish, Takifugu flavipterus. ${ }^{1}$ Toxicity scores are +++: extremely toxic, ++: strongly toxic, + : moderately toxic, and -: nontoxic, as shown in Table $2 .{ }^{2}$ The locations of the captured areas A to G are shown in Figure 2.

\subsection{Relationship between TTX Levels in the Flesh and the Skin}

The relationship between the TTX levels in the flesh (average of outer and inner portions) and skin is shown in Figure 7. Six flesh samples were toxic (>10 MU/g), and these specimens were judged as toxic using randomly collected samples, as described in Section 3.1.

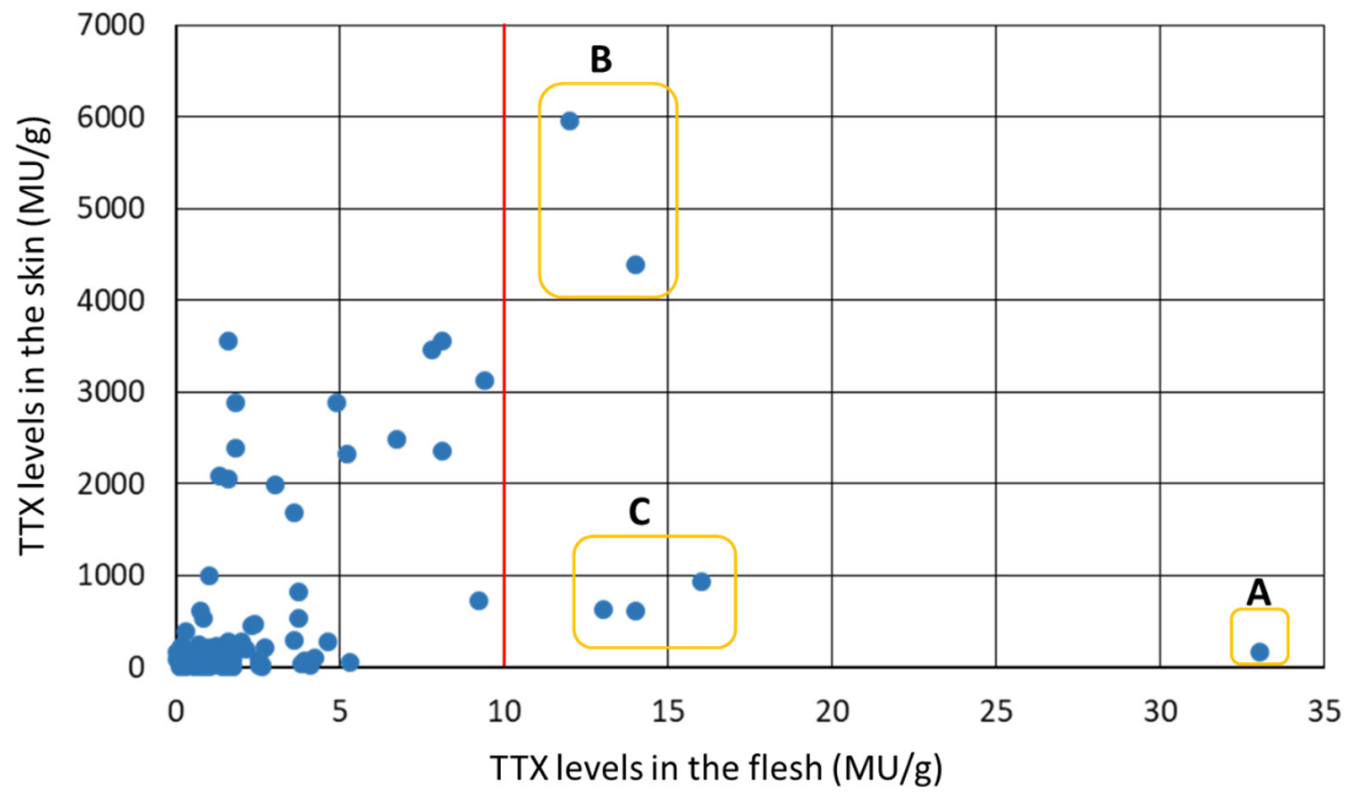

Figure 7. Relationship of TTX levels in the flesh and the skin of the pufferfish, Takifugu flavipterus. A: Specimens with extremely toxic skin; B: specimens were freeze-thawed before cutting into each tissue; C: the condition of the specimen was not good. The red line indicates the level of TTX at $10 \mathrm{MU} / \mathrm{g}(2.2 \mathrm{mg} / \mathrm{kg})$, the limit of toxicity, in the flesh. 
The specimen that was not in good condition was indicated as A in Figure 7, and the TTX level in the skin was $165 \mathrm{MU} / \mathrm{g}(36.3 \mathrm{mg} / \mathrm{kg})$. The level in the skin was not high among the specimens analyzed. From the appearance of this specimen, we guessed that there was a long time between capture and analysis, in which the skin tissues had degraded and TTX had migrated to the flesh. Hence, the appearance of the specimen is an important factor that can help to decide whether the specimen is suitable for human consumption. It should be supposed that pufferfishes have toxic skin if their appearance is poor. In this case, this specimen should not be consumed to avoid intoxication due to the ingestion of toxic levels of TTX in the flesh migrated from the skin.

The two highest TTX levels in the skin were 4500 and $6000 \mathrm{MU} / \mathrm{g}$ (990 and $1320 \mathrm{mg} / \mathrm{kg}$ ); these are indicated as B in Figure 7. These specimens were in good condition and prepared fresh (without freeze-thawing). This observation revealed that TTX might migrate from extremely toxic skin to the flesh, even if the specimen is in good condition and fresh.

Three freeze-thawed samples are indicated as C in Figure 7, and the TTX levels in the skin were from 600 to $950 \mathrm{MU} / \mathrm{g}$ (132 to $200 \mathrm{mg} / \mathrm{kg}$, respectively). There appeared to be no relationship between TTX levels in the flesh and skin, as shown in Figure 7. However, the TTX levels in the flesh and skin of the freeze-thawed specimens before sample preparation were correlated, with a coefficient of determination $\left(R^{2}\right)$ of 0.955 (Figure 8).

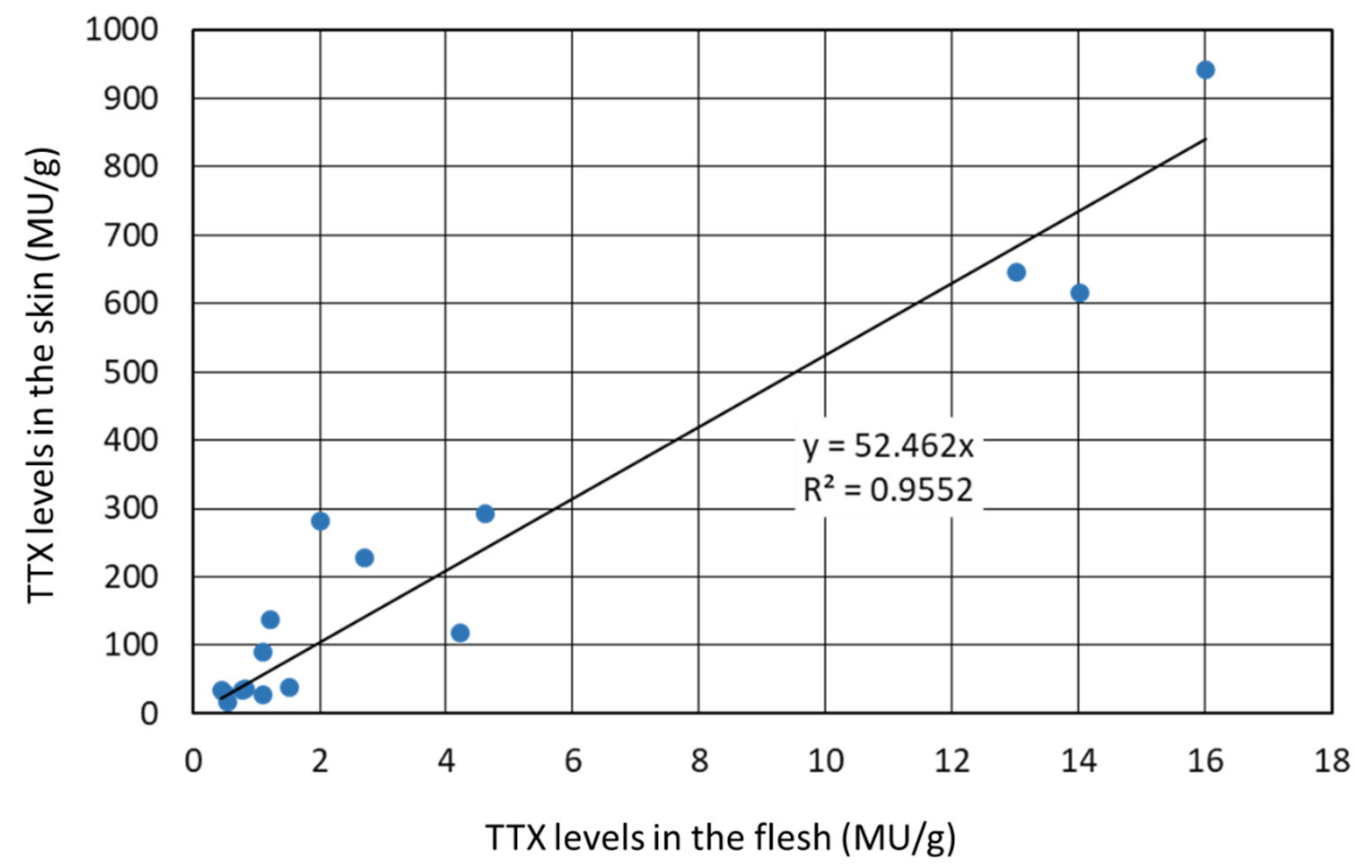

Figure 8. Relationship between levels in the flesh and the skin of the pufferfish, Takifugu flavipterus, when specimens were freeze-thawed before cutting into each tissue.

Shiomi and co-workers demonstrated the migration of TTX from the toxic skin to the flesh in specimen of a pufferfish, Takifugu alboplumbeus (Fugu niphobles in their manuscripts) $[19,20]$. They found that the migration occurred regardless of the freezing method, but was strongly dependent on the thawing method: they detected toxicity in the flesh of the fish thawed at $4{ }^{\circ} \mathrm{C}$, but not in fish thawed rapidly under running water $\left(15{ }^{\circ} \mathrm{C}\right)$ [20]. The maximum toxicity of their rapidly thawed sample was $236 \mathrm{MU} / \mathrm{g}$ in the skin and $6 \mathrm{MU} / \mathrm{g}$ in the flesh [20]. In the present study, the frozen specimens were thawed under running water. Three flesh samples of freeze-thawed specimens were toxic (>10 MU/g), with TTX levels in the skin of more than $600 \mathrm{MU} / \mathrm{g}$ (Figure 8). The TTX levels of the other freeze-thawed specimens were $<300 \mathrm{MU} / \mathrm{g}$ in the skin and $<5 \mathrm{MU} / \mathrm{g}$ in the flesh. Thus, the specimens that accumulate high levels of TTX in the skin should not be freeze-thawed to avoid TTX migration from the toxic skin to the flesh. 


\section{Conclusions}

Our investigation revealed the TTX levels in the flesh and skin of the pufferfish T. flavipterus captured in the Seto Inland Sea and landed in Fukuoka Prefecture. Of the six individuals with toxic flesh ( $>10 \mathrm{MU} / \mathrm{g}$ or $>2.2 \mathrm{mg} / \mathrm{kg}$ ), one was not in good condition, three were freeze-thawed before cutting into each tissue, and two accumulated high levels of TTX (>4500 and $6000 \mathrm{MU} / \mathrm{g}$ or 990 and $1320 \mathrm{mg} / \mathrm{kg}$, respectively) in the skin. The TTX levels in the flesh of the outer part (skin side) were higher than that of the inner part (visceral side). A good correlation $\left(R^{2}=0.955\right)$ was found between the TTX levels in the skin and flesh of the freeze-thawed specimens. The levels of TTX in the skin appeared to be regionally specific. From these observations, we concluded that the migration of TTX from the skin to the flesh was notably in the following cases: (1) in individuals with damaged skin; (2) in individuals subjected to a freeze-thaw process before the toxic skin was removed; and (3) in individuals with extremely toxic skin. These individuals of T. flavipterus should be considered not suitable for human consumption, to avoid intoxication. Our study strongly recommends that toxic portions of $T$. flavipterus should be removed as soon as possible after individuals are caught; moreover, it is also recommended to avoid consuming fish caught from highly toxic areas.

Author Contributions: Conceptualization, N.O. and A.N.; methodology, N.O. and K.K.; validation, N.O. and K.K.; formal analysis, N.O. and K.K.; investigation, A.H., S.Y., T.Y., T.S., N.S. and K.M.; resources, N.O., Y.A. and A.N.; data curation, N.O., A.H., S.Y., T.Y., T.S. and N.S.; writing-original draft preparation, N.O. and K.M.; writing-review and editing, N.O., K.M. and H.A.; visualization, N.O., K.K., S.Y. and A.H.; supervision, H.A.; project administration, N.O.; funding acquisition, N.O. and H.A. All authors have read and agreed to the published version of the manuscript.

Funding: A part of this research was funded by the Ministry of Health, Labour and Welfare (MHLW), Japan, H27-Shokuhin-Ippan-009.

Institutional Review Board Statement: Not applicable.

Informed Consent Statement: Not applicable.

Data Availability Statement: The data presented in this study are available on request from the corresponding author.

Acknowledgments: The authors thank Koichi Akaki, Fukuoka City Institute of Health and Environment, Japan, for helping with the sample collection, and Hiroyuki Motomura, Kagoshima University Museum, Japan, for providing the picture of Takifugu flavipterus. A part of this study was carried out under the practice-based program of Meiji Pharmaceutical University (MPU). This manuscript is dedicated to the late Manabu Asakawa of Hiroshima University.

Conflicts of Interest: The authors declare no conflict of interest. 


\section{Appendix A}

Table A1. Species and parts that can be processed to eliminate health risks ${ }^{1}$.

\begin{tabular}{|c|c|c|c|c|c|}
\hline Family & Species $^{2}$ & Japanese Name & Flesh & Skin & Testis \\
\hline \multirow{16}{*}{ Tetraodontidae } & Takifugu alboplumbeus ${ }^{1}$ & Kusafugu & edible & -3 & - \\
\hline & T. flavipterus 1 & Komonfugu & edible & - & - \\
\hline & T. pardalis & Higanfugu & edible & - & - \\
\hline & T. snyderi & Shosaifugu & edible & - & edible \\
\hline & T. porphyreus & Mafugu & edible & - & edible \\
\hline & T. obscurus & Mefugu & edible & - & edible \\
\hline & T. chrysops & Akamefugu & edible & - & edible \\
\hline & T. rubripes & Torafugu & edible & edible & edible \\
\hline & T. chinensis & Karasu & edible & edible & edible \\
\hline & T. xanthopterus & Shimafugu & edible & edible & edible \\
\hline & T. stictonotus & Gomafugu & edible & - & edible \\
\hline & T. flavidus & Sansaifugu & edible & - & - \\
\hline & Lagocephalus inermis & Kanafugu & edible & edible & edible \\
\hline & L. spadiceus ${ }^{1}$ & Shirosabafugu & edible & edible & edible \\
\hline & L. cheesemanii ${ }^{1}$ & Kurosabafugu & edible & edible & edible \\
\hline & Sphoeroides pachygaster & Yoritofugu & edible & edible & edible \\
\hline \multirow{4}{*}{ Diodontidae } & $\begin{array}{c}\text { Chilomycterus } \\
\text { reticulatus }\end{array}$ & Ishigakifugu & edible & edible & edible \\
\hline & Diodon holocanthus & Harisenbon & edible & edible & edible \\
\hline & D. liturosus & Hitozuraharisenbon & edible & edible & edible \\
\hline & D. hystrix & Nezumifugu & edible & edible & edible \\
\hline Ostraciidae & Ostracion immaculatum & Hakofugu & edible & - & edible \\
\hline
\end{tabular}

Note: the list is valid for the pufferfish caught in the coastal areas of Japan, the Sea of Japan, the Bohai Sea, the Yellow Sea, and the East China Sea. The list is not valid to T. flavipterus and T. pardalis caught in Okirai Bay and Kamaishi Bay in Iwate Prefecture and Ogatsu Bay in Miyagi Prefecture. ${ }^{1}$ The table was modified from the list provided in the notice "New Rules for Measures to Secure Sanitation Regarding Pufferfish" (Kan-Nyu59 of 2 December, 1983) by the Ministry of Health, Labour and Welfare of Japanese Government. The English translation of the titles of the list and the notice followed reference [7]. ${ }^{2}$ The scientific names followed reference [21]. The scientific names previously used were as follows: T. niphobles for T. alboplumbeus [9], T. poecilonotus for T. flavipterus [9], L. wheeleri for L. spadiceus [22], and L. gloveri for L. cheesemanii [23]. ${ }^{3}$ Not edible.

\section{References}

1. Yasumoto, T.; Yotsu-Yamashita, M. Chemical and Etiological Studies on Tetrodotoxin and Its Analogs. Toxin Rev. 1996, 15, 81-90. [CrossRef]

2. Noguchi, T.; Arakawa, O. Tetrodotoxin-Distribution and Accumulation in Aquatic Organisms, and Cases of Human Intoxication. Mar. Drugs 2008, 6, 220-242. [CrossRef] [PubMed]

3. Arakawa, O.; Hwang, D.-F.; Taniyama, S.; Takayani, T. Toxins of pufferfish that cause human intoxications. Coast. Environ. Ecosyst. Issues East China Sea 2010, 227-244.

4. Toda, M.; Uneyama, C.; Toyofuku, H.; Morikawa, K. Trends of Food Poisonings Caused by Natural Toxins in Japan, $1989-2011$. Shokuhin Eiseigaku Zasshi (Food Hyg. Saf. Sci.) 2012, 53, 105-120. [CrossRef] [PubMed]

5. Bane, V.; Lehane, M.; Dikshit, M.; Riordan, A.; Furey, A. Tetrodotoxin: Chemistry, Toxicity, Source, Distribution and Detection. Toxins 2014, 6, 693. [CrossRef]

6. Lago, J.; Rodríguez, L.P.; Blanco, L.; Vieites, J.M.; Cabado, A.G. Tetrodotoxin, an Extremely Potent Marine Neurotoxin: Distribution, Toxicity, Origin and Therapeutical Uses. Mar. Drugs 2015, 13, 6384-6406. [CrossRef]

7. Food Safety Commission of Japan. The Liver of the Aquacultured Japanese Pufferfish (Natural Toxins). Food Saf. 2017, 5, 169-170. [CrossRef] [PubMed]

8. Kodama, M.; Ogata, T.; Kawamukai, K.; Oshima, Y.; Yasumoto, T. Toxicity of Muscle and Other Organs of Five Species of Puffer Collected from the Pacific Coast of Tohoku Area of Japan. Bull. Jpn. Soc. Sci. Fish. 1984, 50, 703-706. [CrossRef]

9. Matsuura, K. Taxonomic and Nomenclatural Comments on Two Puffers of the Genus Takifugu with Description of a New Species, Takifugu flavipterus, from Japan (Actinopterygii, Tetraodontiformes, Tetraodontidae). Bull. Natl. Mus. Nat. Sci. Ser. A 2017, 43, 71-80.

10. Kodama, M.; Sato, S. Pufferfish Poison. In Standard Method of Analysis in Food Sagety Regulation, 2015, Physical and Chemical Methods; Association, J.F.H., Ed.; Japan Food Hygiene Association: Tokyo, Japan, 2015; pp. 813-820.

11. EFSA Panel on Contaminants in the Food Chain. Risks for public health related to the presence of tetrodotoxin (TTX) and TTX analogues in marine bivalves and gastropods. EFSA J. 2017, 15, e04752. 
12. Endo, R. Toxicological studies on puffer fishes: Comparison of toxicities on the various species. J. Toxicol. Sci. 1984, 9 (Suppl. I), 1-11. [CrossRef] [PubMed]

13. Fuchi, Y.; Hoashi, K.; Akaeda, H.; Makino, Y.; Nogcuhi, T. Toxicity of Two Species of Puffer Fishes, Takifugu pardalis ("Higanfugu") and Takifugu poecilonotus ("Komonfugu") Inhabiting the Kunisaki Coast, Oita Prefecture. Food Hyg. Saf. Sci. (Shokuhin Eiseigaku Zasshi) 1999, 40, 80-89. [CrossRef]

14. Ikeda, K.; Emoto, Y.; Tatsuno, R.; Wang, J.J.; Ngy, L.; Taniyama, S.; Takatani, T.; Arakawa, O. Maturation-associated changes in toxicity of the pufferfish Takifugu poecilonotus. Toxicon 2010, 55, 289-297. [CrossRef]

15. Asakawa, M.; Toyoshima, T.; Shida, Y.; Noguchi, T.; Miyazawa, K. Paralytic toxins in a ribbon worm Cephalothrix species (Nemertean) adherent to cultured oysters in Hiroshima Bay, Hiroshima Prefecture, Japan. Toxicon 2000, 38, 763-773. [CrossRef]

16. Asakawa, M.; Toyoshima, T.; Ito, K.; Bessho, K.; Yamaguchi, C.; Tsunetsugu, S.; Shida, Y.; Kajihara, H.; Mawatari, S.F.; Noguchi, T.; et al. Paralytic toxicity in the ribbon worm Cephalothrix species (Nemertea) in Hiroshima Bay, Hiroshima Prefecture, Japan and the isolation of tetrodotoxin as a main component of its toxins. Toxicon 2003, 41, 747-753. [CrossRef]

17. Asakawa, M.; Ito, K.; Kajihara, H. Highly Toxic Ribbon Worm Cephalothrix simula Containing Tetrodotoxin in Hiroshima Bay, Hiroshima Prefecture, Japan. Toxins 2013, 5, 376-395. [CrossRef]

18. Saito, H.; Nakanishi, Y.; Shigeta, T.; Umino, T.; Kawai, K.; Imabayashi, H. Effect of predation of fishes on oyster spats in Hiroshima Bay. Nippon Suisan Gakkaishi (Bull. Jpn. Soc. Sci. Fish.) 2008, 74, 809-815. [CrossRef]

19. Shiomi, K.; Tanaka, E.; Kumagai, S.; Yamanaka, H.; Kikuchi, T.; Kawabata, T. Toxification of Muscle after Thawing of Frozen Puffer Fish. Nippon Suisan Gakkaishi (Bull. Jpn. Soc. Sci. Fish.) 1984, 50, 341-347. [CrossRef]

20. Shiomi, K.; Shibata, S.; Yamanaka, H.; Kikuchi, T. Some Factors Affecting the Toxification of Muscle after Thawing of Frozen Puffer Fish. Nippon Suisan Gakkaishi (Bull. Jpn. Soc. Sci. Fish.) 1985, 51, 619-625. [CrossRef]

21. Matsuura, K. Pufferfishes and Their Allies of Japan; Tokai University Press: Hiratsuka, Japan, 2017.

22. Matsuura, K. Lagocephalus wheeleri Abe, Tabeta \& Kitahama, 1984, a junior synonym of Tetrodon spadiceus Richardson, 1845 (Actinopterygii, Tetraodontiformes, Tetraodontidae). Mem. Natl. Mus. Nat. Sci. 2010, 46, 39-46.

23. Matsuura, K.; Satoh, T.P. Redescription of Lagocephalus cheesemanii (Clarke 1897), a senior synonym of Lagocephalus gloveri Abe and Tabeta 1983, based on morphological and genetic comparisons (Actinopterygii: Tetraodontiformes: Tetraodontidae). Ichthyol. Res. 2017, 64, 104-110. [CrossRef] 